\title{
Synergistic Effect of Ethanolic Extract of Phyllantus Muellerianus and Eremomastax Speciosa Leaves on Lipid Profile of Wistar Rat
}

\author{
*MUONEKE, CV; BAYIM, PR \\ Department of Biochemistry, Faculty of Science, Cross River University of Technology, Calabar, Nigeria \\ *Corresponding Author Email: muonekechinonye@gmail.comTel: +2348107893466 \\ Other Author Email: peterrobbinsbayim@ crutech.edu.ngTel: +23480632993135
}

\begin{abstract}
The study investigated the synergistic effect of ethanolic extract of Eremomastax speciosa and Phyllantus muellerianusleaves on the lipid profile of Wistar rats. The Wistar rats were assigned into two groups of 10 animals each; the control was given normal rat pellet and water, while the experimental group was given the mixture of the ethanolic plant extracts at $200 \mathrm{mg} / \mathrm{kg}$ body weight, by orogastric intubations once daily. The animals were fed for 3 weeks ( 21 days) during which anthropometric measurement and data were collected. Twelve hours after the feeding and administration of both plants extract, the animals were anesthetized under chloroform vapor and then dissected. Blood samples were collected from the heart by cardiac puncture into plain tubes and taken to the laboratory for analysis. The phytochemical result indicates that the extract contains a high amount of flavoniods and alkaloids; a moderate amount of saponins, tannins, and polyphenols with a mild amount of glycosides. The result of the study shows a mean significant decrease in the TC level and LDL-C level; an abnormal increase in the levels of TG, VLDL$\mathrm{C}$, and an abnormal decrease in HDL-C between the experimental and control group at a probability level of $\mathrm{p}<0.05$. The phytochemical result indicates that the plant can be used to manage many health conditions like Stomach troubles, headaches, jaundice, and anemia (Obenet al., 2006). While the overall result of the study reveals that the administration of both extracts has both hypolipidemic effects and hyperlipidemic effects on the lipid profile levels correlate with cardiovascular disease.
\end{abstract}

DOI:https://dx.doi.org/10.4314/jasem.v25i11.1

Copyright: Copyright $\left({ }_{0} 2021\right.$ Muoneke and Bayim. This is an open access article distributed under the Creative Commons Attribution License (CCL), which permits unrestricted use, distribution, and reproduction in any medium, provided the original work is properly cited.

Dates: Received: 22 August 2021; Revised: 17 September 2021; Accepted: 06 October 2021

Keyword: Phyllantus muellerianus, Eremomastax speciosa, Lipid profile, Cholesterol, Cardiovascular disease.

Plants are the richest resource of drugs of traditional systems of modern medicines, nutraceuticals, food supplements, folk medicines, pharmaceutical intermediates, and chemical entities for synthetic drugs. Evans (2002) and Okpuzor et al., (2008) opined that the practice of traditional medicine using medicinal plants is as old as the origin of man. The bioactive ingredients that have the therapeutic activity in plants used in traditional practice are mostly unidentified and traditional healers believe in the holistic nature of their treatment. Some active components present in plants include; anthraquinones, flavonoids, glycosides, saponins, tannins, alkaloids (Perfusion et al., 2014). Plants also contain other compounds such as morphine, atropine, codeine, steroids, lactones, and volatile oils, which possess medical values for the treatment of different diseases (Chevalier, 2000). Since most plants have medicinal properties, it is of utmost importance that their efficacy and toxicity risks are evaluated. This is the case of Eremomastax speciosa, widely distributed in tropical Africa (Dibong et al., 2011). The plant is a robust, polymorphous shrub growing to a height of $2 \mathrm{~m}$. $E$. speciosa is used locally as medicine and cited for its various beneficial effects, which include stomach complaints, dysentery, hemorrhoids, urinary tract infection, painful menstruation, diarrhea, and male and female infertility (Oben et al., 2006 and Telefo et al., 2011), and is commonly referred to as "blood plant" since it is also widely used to treat cases of anemia. In southern Nigeria, the leaves serve as treatment of internal heat, infertility, burns, and hemorrhage in women after birth. The leaves are applied locally to guinea worm's sores to kill the parasite, to relieve pains in headache, and as a poison antidote. Phyllanthus muellerianus originates from Senegal and Guinea Bissau east to Sudan and Kenya; south to northern Angola and northern Mozambique. P.muellerianus is a deciduous or evergreen shrub with numerous stems from the base and sometimes with climbing habits (Igwe et al., 2007). P muellerianus is a medicinal leaf that helps in the treatment of many ailments such as intestinal disorders, jaundice, urethral discharges, and wound dressing. The peppered leaves are used to make a poultice to treat rheumatism, while the seeds are used as a cathartic and roots as a 
purgative. In Nigeria, the young roots with their leafy twigs are given for jaundice and as a mild purgative and to treat urethral discharges. Its powdered roots and bark-decoction are used as a snuff to treat throat pains with glandular fever. Its leaves are also the leaves are boiled with palm fruits and given as soups to women after delivery. In Ivory Coast, the leaves are eaten by men to boost male fertility while In Congo, a leaf decoction is taken for anemia. Phyllanthus muellerianus is also an anti-microbial agent. The plant extract also shows anti-plasmodium falciparum (Kamaraj et al., 2011). The antibacterial activities of the plant have been demonstrated in the leaf and stem bark against some bacteria. In Cameroon, the bark is used as a remedy for tetanus and wound infection. Lipoprotein abnormalities are considered a highly modifiable risk factor for cardiovascular disease (CVD). Cholesterol and triglycerides are the most important plasma lipids, crucial for the formation of the cell membrane, synthesis of hormones, and offer a source of free fatty acids (Feroz et al., 2011). Increased levels of cholesterol and low-density lipoprotein cholesterol (LDLC) usually promote arteriosclerosis while HDL-C retard or prevent the development of arteriosclerosis (Odetola et al., 2004). Therefore, the present study has been specifically designed to evaluate the effects of $P$. muellerianus and E. speciosa on the lipid profile of Wistar rat. The objective of this study is to (a) estimate the serum concentration of total cholesterol in the animals (b) estimate the serum Triglyceride concentration in the animals (c) compare the serum LDL concentration in the animals (d) evaluate the serum HDL concentration in the animals and (e) evaluate the serum VLDL between the groups.

\section{MATERIALS AND METHODS}

Collection and Identification of Plant samples: Fresh matured Eremomastax speciosa and Phyllantus muellerianus were obtained from Awi village in Akampa Local government Area of Cross River state, Nigeria. The plants were identified and authenticated by Dr. Samuel Udo in the Biological Science Department, Cross River University of Technology, Calabar, Nigeria.

Preparation of both plants Extracts: The matured leaves of both plants were properly dried under shade for seven days and then oven-dried for five minutes. The dried leaves of both plants were blended to a fine powder using a mortar and pestle. $25 \mathrm{~g}$ of both blended leaves were weighed using an electronic weighing balance and transferred to a thimble of a soxhlet extractor. The thimble is attached to a condenser which has an inlet were water goes in the setup and an outlet where the water goes out of the setup. $150 \mathrm{ml}$ of solvent (ethanol) was measured using a measuring cylinder and was transferred into a round bottom flask of the soxhlet extractor.

The solvent is heated to reflux through the heating mantle. The solvent vapor travels up through the distillation arm and floods the dried sample in the thimble. The condenser ensures the cooling of the solvent which drips back down into the thimble. The thimble is filled slowly with warm solvent; some of the desired compounds dissolve in a warm water solvent. The thimble chamber is emptied by a siphon, and the solvent returns to the distillation flask (round bottom flask).

The thimble ensures that the rapid motion of the solvent does not transfer any solid material to the round bottom flask. The cycle was allowed to repeat many times, for about four hours until the color of the extract on the arm of the extractor was no longer visible to the human eye.

Note that this preparatory procedure was for both plants extract.

Phytochemical Screening of Ethanolic Extract of Eremomastax speciosa and Phyllantus muellerianus: The following methods were used on the ethanolic extracts for the quantitative identification of the phytochemical components.

Identification of Alkaloids: Sofowora, (1982) method was used. $2 \mathrm{ml}$ of both ethanolic plants extract was taken in different test tubes, and $5 \mathrm{mls}$ of $1 \%$ hydrochloric acid was added to each test tube and steamed on a water bath. $1 \mathrm{ml}$ of each mixture was added to few drops of Mayer's reagent. Another $1 \mathrm{ml}$ of each mixture was added to a few drops of dragendoff's reagent. The presence of turbidity and precipitate with either of these reagents was taken as preliminary evidence for the presence of Alkaloids.

Identification of Flavanoids: Harbone, (1973) method was used. $2 \mathrm{mls}$ of both plants extract were added to a few pieces of aluminum metals and $2 \mathrm{mls}$ of concentrated hydrochloric acid, each. The formation of an orange-red precipitate indicates the presence of flavonoids.

Identification of Tannins: Trease and Evans, (1978) method was used. $2 \mathrm{mls}$ of both aqueous plants extract were stirred separately with $10 \mathrm{mls}$ of distilled water and heated in a water bath. Then, $1 \mathrm{ml}$ of $1 \%$ of $\mathrm{FeCl}_{3}$ was added to these separate mixtures. A blue-green precipitate indicates the presence of tannins. 
Identification of Glycosides: Safowora, (1982) method was used. $2 \mathrm{mls}$ of ethanolic extract of both plants extract were added to $2 \mathrm{mls}$ of sulphuric acid, separately to obtain a lower layer. A reddish-brown coloration at the interface indicates the presence of glycosides.

Identification of Saponins: Safowora, (1982) method was used. $2 \mathrm{mls}$ of ethanolic extract of both plants were distilled with $10 \mathrm{mls}$ of distilled water separately and heated in a water bath, then cooled and shaken vigorously. The presence of stable foam indicates the presence of saponins.

Identification of polyphenol: Harbone, (1973) method was used. $2 \mathrm{mls}$ of ethanolic extract of both plants were added to $5 \mathrm{mls}$ of distilled water and heated for 30 minutes separately in a water bath. Then, $1 \mathrm{ml}$ of $1 \%$ $\mathrm{FeCl} 3$ was added followed by $1 \mathrm{ml}$ of $1 \%$ of potassium ferrocyanide solution. The formation of a green-blue coloration indicates the presence of polyphenol.

Identification of Anthraquinones: Trease \& Evan's (1983) method was used. $2 \mathrm{mls}$ of ethanolic extracts of both plants were shaken in $10 \mathrm{mls}$ of benzene separately. The mixtures were filtered and $5 \mathrm{mls}$ of $10 \%$ ammonia solution was also added. The mixtures were shaken well. A violet coloration in the ammoniacal (lower) phase indicates the presence of anthraquinones.

Identification of steroids: Burchard, (1974) method was used. $2 \mathrm{mls}$ of ethanolic extract of both plants were added in separate test tubes with 10 drops of acetic acid and 2 drops of concentrated $\mathrm{H}_{2} \mathrm{SO}_{4}$. The appearance of red coloration which turns to greenish color with time indicates the presence of steroids.

Experimental Design: Twenty albino rats of Wistar strain weighing between $150 \mathrm{~g}$ and $200 \mathrm{~g}$ were used for this study. The animals were obtained from the animal house of the Animal Science Department, Faculty of Applied Science, Ebonyi State University, Abakaliki. The animals were housed at the Department of Biological Sciences, Animal House, Cross River University of Technology, in wooden cages with wiremesh tops followed by an experimental period of 21days under controlled environmental conditions of temperature $27 \pm 2^{\circ} \mathrm{c}$ and a 12 hour light/dark cycle. The animal room was adequately ventilated and the animals were fed on normal rat chow during the experimental periods.

The Wistar rats were assigned into two groups of 10 animals each. The control was given a normal rat pellet while the experimental group was given the mixture of ethanolic extract of eremomastax speciosa and phyllantus muellerianus at $200 \mathrm{mg} / \mathrm{kg}$ body weight, by orogastric intubations once daily. This lasted for a period of 3 weeks (21 days). They were treated according to the schedule in table 1 .

Table 1: Experimental Design and treatment schedule

\begin{tabular}{lll}
\hline Group & $\begin{array}{l}\text { Numbers } \\
\text { of Animal }\end{array}$ & Treatment \\
\hline Normal Control & 10 & Normal rat pellet \\
Test Group & 10 & Extracts $(200 \mathrm{mg} / \mathrm{kg})$ \\
\hline
\end{tabular}

Collection of Blood Samples for Analysis: Twelve hours after the feeding and administration of both plants extract, the animals were anesthetized under chloroform vapor, and then dissected. Blood samples were collected from the heart by cardiac puncture into plain tubes, with the aid of a $5 \mathrm{ml}$ syringe and needle. The blood samples were then taken to the laboratory for analysis.

Determination of lipid Profile: The Total cholesterol (TC), Triglyceride (TG), Very-low-density lipoprotein (VLDL), Low-density lipoprotein (LDL), and Highdensity Lipoprotein (HDL) were determined using the method of Richmond (1973).

Statistical Analysis: All data are expressed as mean \pm Standard deviation. The student t-test was used to analyze the data. The results were considered significant at $p$ values of less than $0.05(p<0.05)$.

\section{RESULTS AND DISCUSSION}

The phytochemical composition of every food item is a determinant of its pharmacological properties as these secondary metabolites exhibit different degrees of therapeutic effects. The phytochemical analysis of the mixture of both plant extracts where represented in Table 2. They contain a high amount of Alkaloid and Flavanoids; a moderate amount of Saponins, Tannins, and Polyphenols; trace amount of Glycosides; and a negligible amount of Anthraquinone.

Table 2. Phytochemical composition of both plant extracts

\begin{tabular}{l|l|l}
\hline S/N & Phytochemicals & Presence \\
\hline $\mathbf{1}$ & Alkaloids & +++ \\
$\mathbf{2}$ & Saponins & ++ \\
$\mathbf{3}$ & Tannins & ++ \\
$\mathbf{4}$ & Flavonoids & +++ \\
$\mathbf{5}$ & Polyphenols & ++ \\
$\mathbf{6}$ & Glycosides & + \\
$\mathbf{7}$ & Anthraquinone & \\
\hline
\end{tabular}

Key: $+\overline{+++}=$ highly present $;++=$ moderately present $t ;+=$ present in traced amount; - = absent or negligible

Figure 1 reveals the synergistic effect of ethanolic extracts of phyllantus muellerianus and eremomastax speciosa leaves on the lipid profile levels of Wistar rats at the dosage of $200 \mathrm{mg} / \mathrm{kg}$ for 3 weeks. This shows a significant reduction in TC levels and LDL-C 
levels of the experimental animals which are factors that can elevate cardiovascular diseases while an abnormal increase in the levels of TG, VLDL-C, and a decrease in the HDL-C of the experimental group may be due to inflammation and infection in general. This is because some experimental animals had blood coming out from some parts of their body like their anus during the period of extract administration. The results of the study are in line with previous studies which stated that a low level of HDL-C followed by High TG and TC levels were the most prevalent dyslipidemia and were related to BMI (Can et al., 2013). The result also correlates with the findings of Okada et al., (2002) and Azizi et al., (2011) where high TG level, TC, and VLDL levels were similar to previous data but higher than previous studies. Furthermore, the results of this study also support the earlier research of Ross, (1999) which has shown that high plasma concentrations of cholesterol; particularly TG, LDL-C, and VLDL-C are the principal risk and factors for atherosclerosis. There have been correlations among increased LDL-C and atherosclerosis since LDL-C gets deposited in the walls of the blood vessels forming atherosclerotic plaque. Some studies recommend that lowering LDL$\mathrm{C}$ reduces the risk of coronal heart disease (Aghasadeghi et al., 2008). The main identified determinants of hyperlipidemia are increased LDL-C and reduced HDL-C (Ghasi et al., 2000 and Ugwu et al., 2013). Thus, any attempt to lower serum concentrations of LDL-C and increased HDL-L concentration is considered as one of the strategies that can hinder or delay the onset of chronic disorders that are associated with hyperlipidemia in humans. Some studies on lipid profile have also shown a significant increase in the mean HDL-C level in the experimental group when compared with the control group which is positive as HDL-C has a protective effect against cardiovascular disease (Ahmed et al., 2013). HDL-C (good cholesterol) removes excess LDL-C (bad cholesterol) from blood circulation and carries it back to the liver where it is degraded or converted into bile acid.

Table 2: T-test for lipid profile between group treated with eremomastax speciosa and phyllantus muellerianus extracts (test group) and untreated group (control).

\begin{tabular}{llllll}
\hline $\begin{array}{l}\text { Group/para } \\
\text { meter }\end{array}$ & $\begin{array}{l}\text { TC } \\
(\mathbf{m m o l} / \mathbf{L})\end{array}$ & $\begin{array}{l}\text { TG } \\
(\mathbf{m m o l} / \mathbf{L})\end{array}$ & $\begin{array}{l}\text { LDL } \\
(\mathbf{m m o l})\end{array}$ & $\begin{array}{l}\text { HDL } \\
(\mathbf{m m o l} / \mathbf{L})\end{array}$ & $\begin{array}{l}\text { VLDL } \\
(\mathbf{m m o l} / \mathbf{L})\end{array}$ \\
\hline $\begin{array}{l}\text { Control } \\
\text { phyllanthus\&e }\end{array}$ & $1.30 \pm 0.06$ & $0.37 \pm 0.24$ & $0.84 \pm 0.58$ & $0.33 \pm 0.15$ & $0.17 \pm 0.01$ \\
$\begin{array}{l}\text { remomastax } \\
\text { non-induced }\end{array}$ & $1.04 \pm 0.30^{*}$ & $0.59 \pm 0.77^{*}$ & $0.57 \pm 0.67^{*}$ & $0.26 \pm 0.01^{*}$ & $0.22 \pm 0.44$ \\
\hline \multicolumn{5}{c}{ Key:Df= $18, n=20 ;$ Confidence level $(p<0.05) ;$ SEM= Standard Error Mean }
\end{tabular}

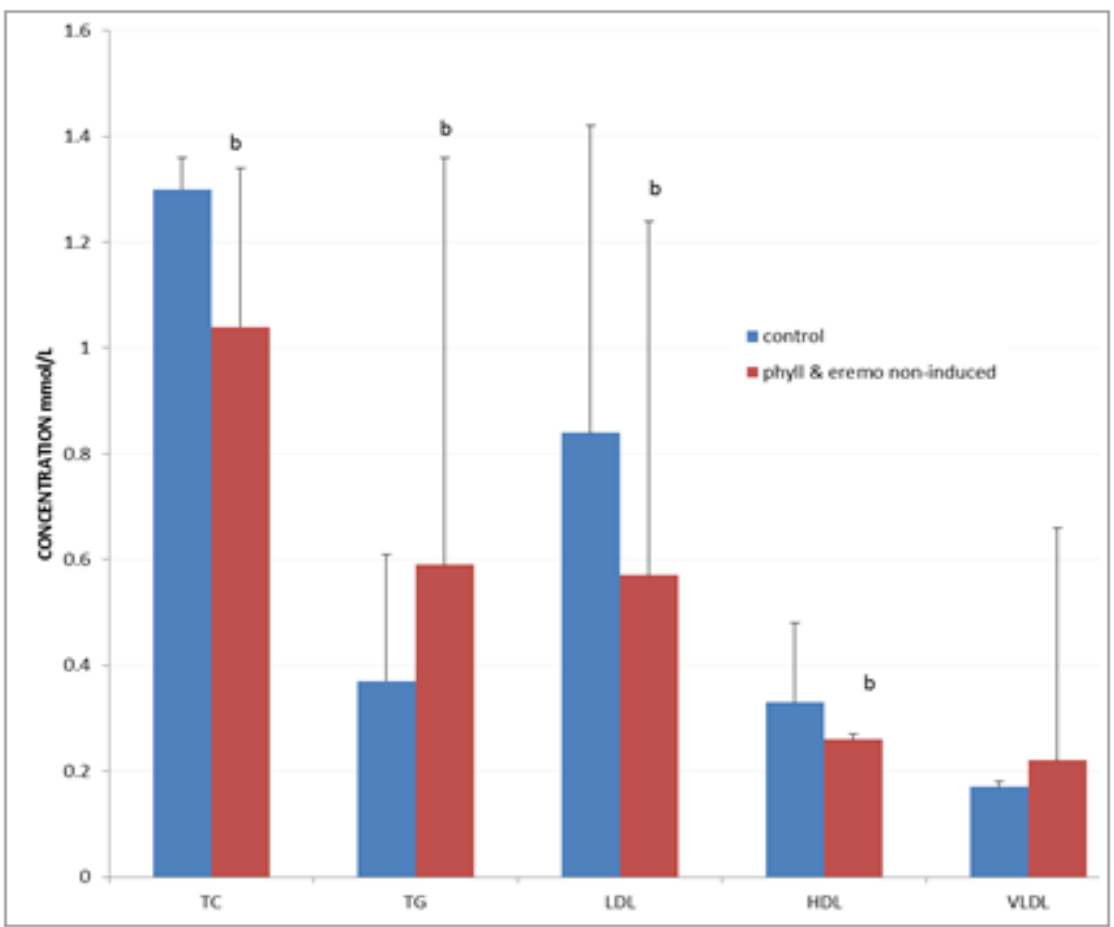

Fig1. The mean lipid concentration of Wistar albino rat fed with combined ethanolic extract of phyllantus muellerianus and eremomastax speciosa. 
The result of student t-test according to FIG 1 shows a statistically significant mean difference in lipid profile between the group treated with a mixture of Eremomastax speciosa and Phyllantus muellerianus extracts and the untreated group (control) at a probability level of $\mathrm{p}<0.05$ equal variances assumed as there was a significant increase and decrease in the lipid profile levels of the group treated with the mixture of both extracts as compared to the control.

Conclusion: It is evident that the phytochemical component of both combined plant extracts support previous research which indicated that the plant may be used to manage health conditions like stomach troubles, headache, jaundice, and anemia. The extracts also had appreciable effects on the lipid profile level by decreasing the plasma level concentration of cholesterol; particularly TC and LDL-C which are principal risks and factors for atherosclerosis.

\section{REFERENCES}

Azizi, F; Rahmani, M; Madjid, M; Allahverdian, S; Ghanbili, J; Ghanbarian, A; Hajipour, R (2001). Serum lipid levels in an Iranian population of children and adolescents: Tehran lipid and glucose study. EurEpidemiol. 17:281-8.

Aghasadeghi, K; Zarei-Nezhad, M; Keshavarzi, A; Mehrabani, D (2008). The prevalence of coronary risk factors in Iranian or migrating tribe. Arch. Iran Med. 11(3): 322-325.

Ahmed, A; Husain, A; Mujeeb, M; Khan, SA; Najmi, AK; Siddique, NA; Damanhouri, ZA; Anwar, F (2013). A review of therapeutic potential of Nigella Sativa: A miracle herb. Asian Pac J. Trop. Bimed. 3:337-352.

Aziz, Z; Tey, NP (2009). Herbal medicines: Prevalence and predictors of use among Malaysian adults. Complement. Ther. Med. 17(1): 44-50.

Chevalier, A (2000). Natural Health Encyclopedia of Herbal Medicine. Darling Kindersley Ltd, New York. 2: 236240.

Can, M; Piskin, E; Guven, B; Acikgoz, S; Mungan, G (2013). Evaluation of serum lipid levels in children. PediatrCardiol. 34:566-9.

Dibong, SD; Mpondo, ME; Ngoye, A; Priso, RJ (2011). "Modalities of exploitation of medicinal plants in Douala's region," The American Journal of Food and Nutrition. 1(2) : 67-73.

Evans, WC (2002). Trease and Evans Pharmacognosy. W. B. Saunders, Edinburg, 15th edition Pp 585-600.

Feroz, Z; Khan, RA; Afroz, S (2011). Adverse effects of antiepileptic, antihypertensive, antidiabeticand antiarrhythmic drugs on hematological and hepatic parameters. Lat. Am. J. Pharm. 30(2): 229-236.

Ghasi, S; Nwobodo, E; Ofili, JO (2000). Hypocholesterolemic effect of the crude extract of leaves of moringaoleifera Lam in high fat diet wistar rats. J. Ethnopharmacol. 69:21-25.

Igwe, CU; Nwaogu, LA; Ujuwondu, CO (2007). Assessment of the hepatic effects, phychemical and proximate compositions of phyllantus amarus. Afr. J. Biotech. 6: 728

Kamaraj, C; Bagavan, G; Elago, G; Zahir, AA; Rajakumar, G; Marimuthu, S; Santhoshkumar, T; Raahuman, AA (2011). Larvicidal activity of medicinal plant extract against Anopheles subpictus \& culextritaeniorhynchus. Indian J Med Res. 134: 101-6.

Malla, RJ (2011). Phytochemical Extraction and Antimicrobial Properties of Different Medicinal Plants: Ocimum sanctum (Tulsi), Eugenia Caryophyllata (clove), Achyranthesbidentata (Datiwan) and Azadirachtaindica(Neem). J. Microbiol. Antimicrob.3 (1): 1-7.

Oben, J; Assi, SE; Agbor, G; Musoro, DF (2006). Effects of eremomastaxspiciosa on experimental diarrhea. Afri. $J$. Trad CAM; 3:95-100

Okpuzor, J; Adebesin, O; Ogbunugafor, H; Amadi, IM (2008). The Potential of Medicinal Plants in Sickle Cell Disease Control: A Review. IntegratedJ. Biomed. Health Sci. 4 (2):47-55.

Odetola, AA; Iranloye YO; Akinloye, O (2004). Hypolipidaemic potentials of solanummelongena and solanumgilo on Hypercholesterolemic Rabbits. Pakistan J. Nutr. 3(3): 180-187

Perfusion, AA; Tan, PV; Ernestine, N; Barthelemy, N (2014). "Antisecretory action of the extract of the aerial parts of Eremomastax speciosa (Acanthaceae) occurs through antihistaminic and anticholinergic pathways," Advances in PharmacologicalSciences. Article ID 323470, 10 pages.

Ross, R (1999). Atherosclerosis- An Inflammatory Disease. N. Engl. J. Med. 340(2): 115-126.

Telefo, PB; Lienou, LL; Yemele, MD; Lemfack, MC; Mouokeu, C; Goka, CS; Tagne, SR; Moundipa FP (2011). "Ethnopharmacological survey of medicinal plants used in women infertility treatment in FossongWentcheng and Fotovillages, Western Region of Cameroon," Phytotherapie, vol. 10(1):25-34.

Ugwu, O; Nwodo, OF; Parker, J; Odo, CE (2013), Effects of ethanolic leaf extract of moringaoleifera on lipid profile of mice. Res. J. Pharm. Biol. Chem. Sci 4(1):324-1332. 